\title{
Sixth- and Tenth-Year Growth Measurements for Three Tree Species in a Load-Bearing Stone-Soil Blend Under Pavement and a Tree Lawn in Brooklyn, New York, U.S.
}

\author{
Jason Grabosky and Nina Bassuk
}

In 1997, willow oak (Quercus phellos L.), swamp white oak (Quercus bicolor Willd.), and goldenraintree (Koelreuteria paniculata Laxm.) were planted in the right-of-way on Lorimer Street in Brooklyn, New York, U.S. This was one of the earliest commercial installations of the load-bearing stone-soil blends (hereafter called structural soil) developed at Cornell University's Urban Horticulture Institute (Grabosky and Bassuk 1995). The north-south street segment bisects McCarren Park between Driggs Avenue and Bayard Street. Trees were planted as 5.1 to $7.6 \mathrm{~cm}$ ( 2 to $3 \mathrm{in}$ ) caliper trees on either side of the street. The west side trees were planted in a continuous trench of structural soil $0.6 \mathrm{~m}(2 \mathrm{ft})$ deep by $2.1 \mathrm{~m}(6.9 \mathrm{ft})$ wide down the entire block. The structural soil was used as the sidewalk base capped with concrete. Tree openings were $0.9 \mathrm{~m}$ by $1.5 \mathrm{~m}(3 \times 5 \mathrm{ft})$, which were planted after paving and then covered by granite unit block pavers. The east side of the street was a tree lawn planted with the same tree species. The site and the trees have been observed and measured in 1999, 2000, 2003, and 2007. After 3 years, there were no substantial differences in either shoot extension growth or foliage quality between the two sites for the oak species (Grabosky et al. 2002). Goldenraintree was not analyzed or reported in the third year set. This article discusses the trees as observed in Year 6 (2003) and Year 10 (2007).

\section{MATERIALS AND METHODS}

Tree height and trunk diameter at $1.4 \mathrm{~m}(4.6 \mathrm{ft})$ were measured on 22 July 2003 and 29 August 2007. Canopy width was measured parallel and perpendicular to the street during the 2007 observation. Comparisons between treatments within observation year used all trees of the species that were in place at the beginning of the study or verified as in place in 1997 to 1998. Imbalance in the number of species replicates on each site (Table 1) required each species to be compared with a nonparametric Mann-Whitney confidence interval test on median treatment response measures conducted in Minitab 14 (Minitab Inc., State College, PA, U.S.).

\section{RESULTS}

Notes from each observation year were used to construct an estimate of mortality in the paved and tree lawn locations. Of a total of 35 trees in the sidewalk, four total trees were presumed dead over the 10 -year period. One $Q$. phellos was labeled dead and removed in 1999 and replaced in 2000. This replicate was noted as having been planted too deep in 2000 and showed chlorotic, stunted growth in 2000, 2003, and 2007 and was removed from analysis. Three other trees in the sidewalk, one other $Q$. phellos and two K. paniculata, died between 2000 and 2003 and have not been replaced. Overall mortality was four of 35 trees $(11 \%)$.

In the tree lawn, failed trees were replaced and additional trees were established in the site over the first three observations. Planting spaces and replacements were tracked by data sheet site maps and verified with tree tag records when observed on site. The initial 1999 observation measured 26 trees in the tree lawn

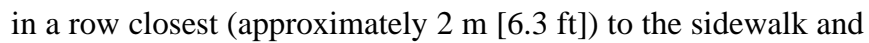
noted high mortality in willow oak (five of the initial ten were dead). Several blank planting holes (empty mulch circle with disturbed soil) were noted in 1999, 2000, and 2003. Death of some replacements in 2000 prompted mapping and tracking of additional trees (a second row of trees at the other edge of the lawn strip), many of which could be verified as 1998 spring replacement or original 1997 planting. The data analysis used the 17 remaining trees of the original 26 trees measured in 1999 from a total analysis record of 41 trees present in 2007. New plants, replacements, other species, trees in park entrance zones (surrounded by pavement), and verified tenth-year trees without measurements from both 2003 and 2007 have been omitted from this research note. Of the original 26 trees, nine have died, three additional dead/missing trees in the line have been replaced, and two replacement trees have died, suggesting a total of 12 dead from 29 initially planted, or $41 \%$ mortality, and two dead from those replaced.

For those that survived, there were no significant differences in size between trees planted in the tree lawn or the sidewalk in Years 6 and 10 (Table 1). This is consistent with earlier observations in Year 3 (Grabosky et al. 2002). Increase in trunk diameter in $Q$. phellos from Year 6 to Year 10 was generally 10 to $13 \mathrm{~cm}$ (4 to $5.2 \mathrm{in}$ ), comparable to forest conditions (Schlaegel 1990). Similarly, $Q$. bicolor increases of 6 to $6.5 \mathrm{~cm}$ (2.4 to 2.6 in) of trunk diameter growth were comparable to observations in Ohio from high-quality urban and forest lot measures (Quigley 2004). Height increase, as an estimator of shoot growth, on the 
Table 1. Tree diameter, height, and width at 6 and 10 years after planting. ${ }^{2}$

\begin{tabular}{|c|c|c|c|c|c|c|c|}
\hline & \multirow[b]{2}{*}{$\mathrm{n}$} & \multicolumn{2}{|c|}{ Tree dbh $(\mathrm{cm})$} & \multicolumn{2}{|c|}{ Tree height (m) } & \multicolumn{2}{|c|}{ Canopy width (m) } \\
\hline & & Mean \pm SE & Median & Mean $\pm \mathrm{SE}$ & Median & Mean \pm SE & Median \\
\hline \multicolumn{8}{|l|}{ 2007, Year 10} \\
\hline Pavement & 14 & $15.1 \pm 0.6$ & $15.0^{N S}$ & $5.9 \pm 0.2$ & $6.1^{N S}$ & $5.1 \pm 0.3$ & $5.3^{N S}$ \\
\hline Tree lawn & 7 & $14.9 \pm 1.0$ & $14.2^{N S}$ & $6.5 \pm 0.4$ & $6.4^{N S}$ & $4.3 \pm 0.4$ & $4.3^{N S}$ \\
\hline \multicolumn{8}{|c|}{ Quercus phellos } \\
\hline \multicolumn{8}{|c|}{ Koelreuteria paniculata } \\
\hline Pavement & 7 & $17.2 \pm 0.6$ & $17.1^{N S}$ & $5.9 \pm 0.3$ & $5.4^{N S}$ & $6.7 \pm 0.3$ & $6.5^{N S}$ \\
\hline Tree lawn & 2 & $16.8 \pm 1.2$ & $16.8^{N S}$ & $6.5 \pm 0.1$ & $6.5^{N S}$ & $6.5 \pm 0.5$ & $6.5^{N S}$ \\
\hline \multicolumn{8}{|l|}{ 2003, Year 6} \\
\hline \multicolumn{8}{|c|}{ Quercus bicolor } \\
\hline Tree lawn & 8 & $9.7 \pm 0.5$ & $9.9^{N S}$ & $5.3 \pm 0.1$ & $5.3^{N S}$ & & \\
\hline \multicolumn{8}{|c|}{ Koelreuteria paniculata } \\
\hline Pavement & 7 & $10.9 \pm 0.4$ & $10.7^{N S}$ & $4.7 \pm 0.1$ & $4.7^{N S}$ & & \\
\hline Tree lawn & 2 & $10.2 \pm 0.5$ & $10.2^{N S}$ & $4.3 \pm 0.2$ & $4.3^{N S}$ & & \\
\hline
\end{tabular}

${ }^{z}$ Means and standard errors are listed to indicate species-treatment variability. Two sample Mann-Whitney tests on medians in nonparametric analysis at $\alpha=0.05$ showed no significant differences $\left({ }^{N S}\right)$ between treatments. Canopy width was not collected in 2003.

$\mathrm{dbh}=$ diameter at breast height; $\mathrm{SE}=$ standard error.

K. paniculata was comparable with anecdotal landscape growth estimations of 0.31 to $0.46 \mathrm{~m}$ ( 1 to $1.5 \mathrm{ft}$ ) growth in height per year in a rounded form to a maximum size of 9.2 to $10.8 \mathrm{~m}(30.4$ to $35.6 \mathrm{ft}$ ). There is general agreement in mature size for the species in the northeast U.S. region (Gerhold et al. 1993; Bassuk et al. 2003). Goldenraintrees on the test site increased in height 1.2 to $2 \mathrm{~m}$ ( 4 to $6.6 \mathrm{ft}$ ) in four seasons and are $55 \%$ to $65 \%$ of their expected mature size in the 10 years since planting.

\section{CONCLUSIONS}

After 10 years, trees growing in the paved situation (in a structural soil) were growing in a manner visually comparable with trees growing in a grassy tree lawn on the same project across the street. The growth observed in both situations is comparable to species growth expectations in nonurban situations. There has been higher mortality in the tree lawn, which could be explained by maintenance and infrastructure repair activities rather than treatment differences.

Acknowledgments. Many thanks to Fiona Watt, Chief of Forestry and Horticulture, City of New York Parks and Recreation, for her assistance and permissions throughout the study from the installation/design phase. We also thank the students and staff who collected data in the 1999 and 2000 visits and Greg Dahle, graduate student; Jess Sanders, graduate student; Mike Gallagher, undergraduate honors student; and Carolyn Haines, student laboratory associate for assistance in the 2007 data collection.

\section{LITERATURE CITED}

Bassuk, N., D.E. Curtis, B.Z. Marranca, and B. Neal. 2003. Recommended Urban Trees: Site Assessment and Tree Selection for Stress Tolerance. Urban Horticulture Institute, Ithaca, NY. 128 pp.
Gerhold, H.D., N.L. Lacasse, and W.N. Wandell. 1993. Street Tree Factsheets. Municipal Tree Restoration Program, Penn State College of Agriculture, University Park, PA.

Grabosky, J., and N. Bassuk. 1995. A new urban tree soil to safely increase rooting volumes under sidewalks. Journal of Arboriculture 21:187-201.

Grabosky, J., N. Bassuk, and B.Z. Marranca. 2002. Preliminary findings from measuring street tree shoot growth in two skeletal soil installations compared to tree lawn plantings. Journal of Arboriculture 28: 106-108.

Quigley, M.F. 2004. Street trees and rural conspecifics: Will long-lived trees reach full size in urban conditions? Urban Ecosystems 7:29-39.

Schlaegel, B.E. 1990. Quercus phellos L. In: Burns, R.M., and B.H. Honkala, tech. coords. Silvics of North America: Vol 2, 877. Hardwoods. Agriculture Handbook 654. U.S. Department of Agriculture, Forest Service, Washington, DC. p. 1383.

Jason Grabosky (corresponding author)

Associate Professor

Ecology, Evolution and Natural Resources

Rutgers University

14 College Farm Road

New Brunswick, NJ 08901, U.S.

grabosky@aesop.rutgers.edu

Nina Bassuk

Professor and Program Leader

Urban Horticulture Institute

Cornell University

Ithaca, NY 14853, U.S. 